\title{
NeUtralizaÇÃo das Átonas
}

(The Neutralization in Portuguese)

Leda BISOL

(PUC-RS)

Abstract: The phonological system of Brazilian Portuguese has two rules of neutralization in favor of high vowels and not three, as it has been postulated. The asymmetrical subsystem of four pos- tonic vowels in nonfinal position is only an effect of frequency, for both middle vowels le, ol are shown to be sensitive to raising. It seems to be a case of expansion of the minimum system of three vowels which, in search of regularization, causes variation between two subsystems, the one with five and the one with three vowels. This paper is developed in the non-linear framework and the data are results of variable rule analysis.

KEY-WORDS: mid vowels, neutralization, variation.

RESUmo: O sistema fonológico do português brasileiro possui duas regras de neutralização em favor da vogal alta e não três, como se vinha postulando. $O$ subsistema assimétrico de quatro vogais da postônica nãofinal é apenas um efeito de freqüência, pois ambas as vogais médias le,ol mostram-se sensíveis a alçamento. Tudo indica que se trata de expansão do sistema mínimo de três vogais que, em busca da regularização, cria variação entre dois subsistemas, o de cinco e o de três vogais. $O$ artigo desenvolve-se na linha da fonologia não-linear, considerando dados resultantes de análise de regra variável.

Palavras-Chave: vogais médias, neutralização, variação.

\section{Introdução}

A interpretação da elevação da vogal média como neutralização deve-se a Câmara Jr. (1977) que, chamando atenção para a variedade de timbre das átonas, em seu dizer de complexidade apenas aparente, explica-a, seguindo o conceito da Escola de Praga nos termos seguintes:

Estabelecidos os fonemas na pauta tônica por sua função distintiva em número de sete $/ \mathrm{i}, \mathrm{u}, \mathrm{e}, \mathrm{o}, \varepsilon, \mathrm{\jmath}, \mathrm{a} /$, o sistema fica reduzido nas demais pautas por neutralização, ou seja, por perda do traço que distingue entre si dois fonemas. Disso emanam subsistemas de cinco, quatro e três vogais , respectivamente, pretônica, postônica não-final e final. Na pretônica, perde- 
se a distinção entre e/ع e o/o, resultando cinco vogais átonas: /i, u, e, o, a/ : belo>beleza; sol>solar; na átona não-final, o/u perdem o traço que os distingue, fósfuro, abóbura, ficando quatro vogais /i, u, e, a/; e, em posição final de palavra, reduz-se o sistema a três: /a, i, u/, verdi, bolu, casa. A passagem de um subsistema para outro é identificada pela elevação gradual da vogal média $(\varepsilon\lrcorner>$, e, o $>\mathrm{i}, \mathrm{u})$ que ocorre de acordo com o grau de enfraquecimento da sílaba: as pretônicas são relativamente menos fortes do que as tônicas e as átonas postônicas são as mais fracas. Fica, pois, o sistema das primeiras com cinco vogais enquanto as finais se reduzem a um sistema de três vogais. Como os valores forte/fraco emergem da atribuição do acento primário, o processo tem por domínio a palavra prosódica. É o que está representado na figura 1 :

(1) A neutralização, segundo Câmara Jr. (1977)

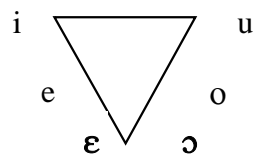

a

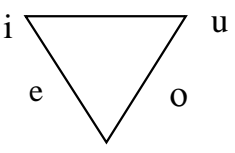

a

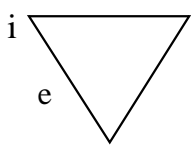

a

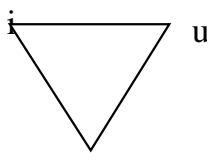

a

Adepto da teoria autossegmental, Wetzels(1992) reinterpreta Mattoso Câmara, explicando a neutralização da seguinte forma: Definidas as vogais em termos da geometria de Clements, com altura vinculada a traços de abertura, aberto 1, aberto 2 e aberto 3, o traço neutralizado é desligado e substituído pelo valor oposto. Dessa forma, paulatinamente, neutraliza-se o sistema de sete para cinco, quatro e três vogais, aplicando-se cada neutralização, uma por vez, de acordo com seu domínio restrito: palavra fonológica, pé métrico e fronteira vocabular, respectivamente, pretônica, postônica não-final e postônica final. As regras estão representadas em (2).

(2) A neutralização, segundo Leo Wetzels (1992)

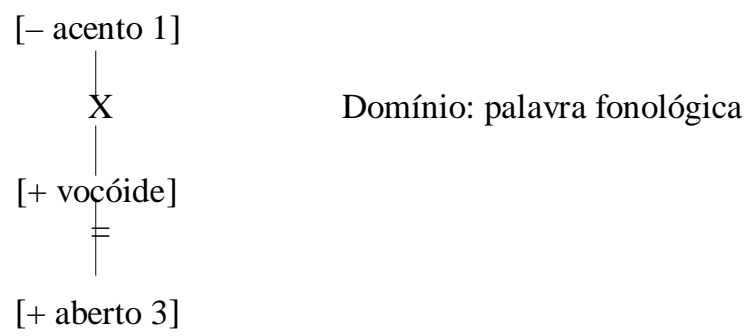

Neutralização da Vogal Átona 


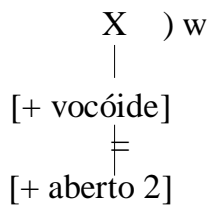

Neutralização de Vogal Postônica Final

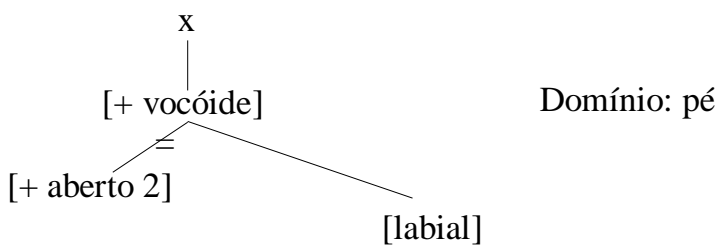

Neutralização da Vogal Postônica não-Final

Feita essa introdução, chegamos ao ponto que queremos pôr em relevo. Se tomarmos para reflexão os registros de altura vocálica do modelo de Clements (1991), exposto em (3) para as línguas românicas, vemos que o português se classifica como uma língua de registro terciário, sete vogais, que se reduz a registro secundário, cinco vogais, no subsistema da pretônica e a registro primário, três vogais, no subsistema da átona final.

(3) Línguas românicas

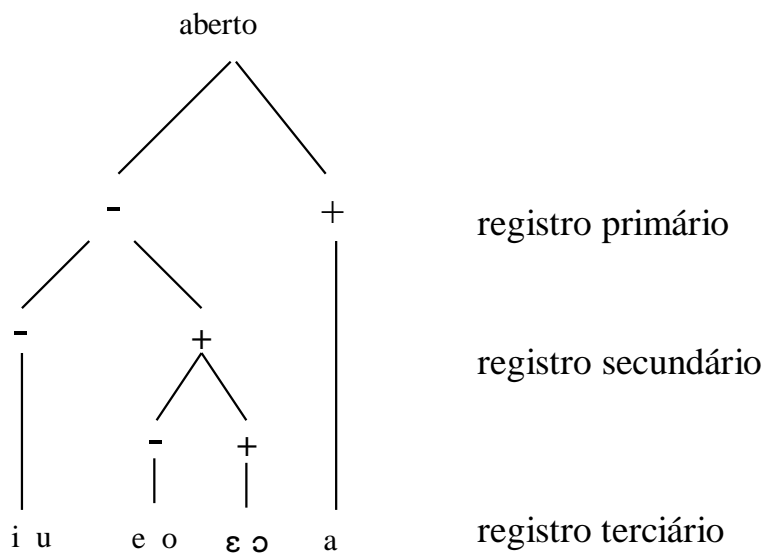

Trata-se, pois, de um sistema de sete vogais, cujos traços relativos à altura, estão especificados em (4) por meio de traços de abertura, em que a 
distinção entre as médias somente se manifesta na pauta tônica.

(4) aberto 1
aberto 2
aberto 3

$\begin{array}{cc}\mathrm{i} / \mathrm{u} & \text { e/o } \\ - & - \\ - & + \\ - & -\end{array}$

e/o $\varepsilon / \mathbf{J}$

$-$

$+$

$+$

(Wetzels, 1992, p.22)

\section{Neutralização da pretônica}

A primeira distinção a ser abandonada, ou seja, a primeira neutralização é a das vogais médias e/ $\varepsilon, \mathrm{o} / \mathrm{\jmath}$, que ocorre na passagem da tônica para átona, configurando-se a mudança de registro terciário para secundário, sem fazer pulos, mudança que vai em direção à generalidade, pois são comuns línguas com cinco vogais, entre as quais o latim clássico e o espanhol. Regras de neutralização são processos naturais e seu resultado é sempre um sistema mais simples, já contido na própria língua e que se encontra em muitas outras línguas do mundo. O resultado é um sistema átono de cinco vogais, uma classe natural: /a, e, i, o, u/, o segundo triângulo representado em (1).
(5) a. b elo > beleza
b. rimar versus rumar
mole > moleza
prever versus prover
tela > tecelão
soldado versus saldado
/i/ $/ \mathrm{u} /$
le/ $/ \mathrm{o} /$
/a/

Essa neutralização aplica-se em todo o sistema, de forma categórica, independentemente da vogal média escolhida para a sua manifestação externa, [-ab3], comum a dialetos que se estendem do centro para o sul ou [+ab3], comum a dialetos que se estendem do centro para o norte.

No entanto a proposta das duas outras neutralizações precisa ser revista, sobretudo se levarmos em conta resultados de análises relativamente recentes. Comecemos pela átona final, tomando como ponto de discussão a elevação da vogal /e/ com base em dados do projeto VARSUL.

\section{Neutralização da Átona Final}

$\mathrm{Na}$ amostra em consideração, (Vieira 2002), a elevação da vogal átona final /e/ que se mostra de uso geral em Porto Alegre, apresenta-se nas demais regiões como regra de aplicação variável. 


\begin{tabular}{l|c|c|c|c}
\hline & Fator & Aplic./Total & $\%$ & Peso Relat. \\
\hline Rio Grande do Sul & Porto Alegre & $48 / 59$ & 81 & 0,99 \\
& Panambi & $10 / 43$ & 23 & 0,29 \\
& São Borja & $33 / 82$ & 40 & 0,44 \\
& Flores da Cunha & $21 / 115$ & 18 & 0,22 \\
\hline Santa Catarina & Florianópolis & $35 / 61$ & 57 & 0,66 \\
& Blumenau & $48 / 77$ & 62 & 0,72 \\
& Chapecó & $27 / 107$ & 25 & 0,25 \\
& Lages & $11 / 44$ & 23 & 0,29 \\
\hline Paraná & Curitiba & $37 / 100$ & 37 & 0,45 \\
& Pato Branco & $40 / 57$ & 70 & 0,81 \\
& Irati & $16 / 76$ & 21 & 0,25 \\
& Londrina & $25 / 56$ & 45 & 0,48 \\
\hline
\end{tabular}

Tabela 1: Elevação da Vogal /e/ - Resultados por cidade (Vieira 2002: 153)

Trata-se da terceira neutralização, a da átona final, envolvendo as vogais /e,o/ que, na mudança de um sistema secundário para um sistema primário, apresenta alofonia nos dados do VARSUL: há variedades de fala que a praticam opcionalmente, até mesmo escassamente. Curitiba, entre as capitais, é um exemplo; há outras que a praticam categoricamente, como Porto Alegre, que se opõe às demais regiões do Estado que dela fazem uso variável. Essa regra tem as características da neutralização: implica mudança de registro, vai em direção à generalidade e cria um sistema vocálico natural que existe dentro da própria língua e em outras, /i, u, a/, como existe no árabe clássico, citado por Clements. Mas o que as análises vêm revelando é que o processo nesta posição apresenta flutuações, em algumas variedades do português brasileiro, indicando que não chegou a sua completude: verde verdi; solo $\sim$ solu. Todavia, tendo em vista que para muitas variedades de fala é regra geral, tome-se por exemplo, o dialeto carioca (Câmara Jr., 1977) ou Porto Alegre (Vieira, 2002), essas flutuações sinalizam um processo de mudança em direção ao subsistema mais simples.

Com base nesses dados, é possível afirmar que no português brasileiro, como um todo, a neutralização da átona final é um processo em andamento no que diz respeito à opção pela vogal alta, uma vez que a variação permanece em certas comunidades. Note-se, todavia, que a neutralização entendida como perda do traço distintivo entre vogais médias e altas é uma regra geral nesta posição, e que a preferência à realização da vogal alta tende a generalizar-se. O contraste fonológico fica restringido a três vogais, independentemente do alofone que se realiza. Exemplos que mostre, como a pretônica o faz, a relação entre a vogal neutralizada e a preservada do tipo bElo > beleza dificilmente podem ser encontrados, pois o português não mantém a vogal temática no processo derivativo. As descrições falam em 
regra de apagamento da vogal temática que ocorre toda vez que ao radical se junta um sufixo começado por vogal. ${ }^{1}$ O fato é que o sistema possui nesta pauta três vogais distintivas:

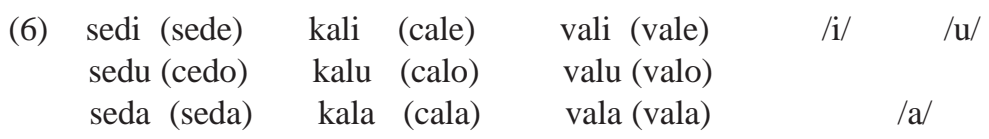

\section{Neutralização da Postônica Não-final}

O problema reside na neutralização da postônica não-final que, na versão mattosiana, reduz o sistema da série posterior, criando um conjunto assimétrico, não-natural /a, u, e, i/ que na fonologia do português dificilmente se justificaria como contexto de regra e que não corresponde a nenhuma mudança de registro identificável em ( 3).

Essa assimetria pode ser explicada em termos fisiológicos. Basta lembrar o diagrama das vogais cardinais de Daniel Jones que atribui menor espaço bucal às posteriores. As vogais /o,u/ estão mais próximas uma da outra do que as vogais /e, i/. Segundo Martinet (1964:139), dado um sistema com o mesmo número de fonemas na serie posterior e anterior, as margens de segurança são mais estreitas na série posterior do que na série anterior, o que pode explicar em parte a diferença de comportamento entre as duas séries.

Embora haja explicação para essa assimetria, esse fato, com respeito ao português brasileiro, merece atenção. Como vemos na Tabela 3, a elevação de /e/ na postônica não-final também se manifesta, não estando, pois, o alçamento restrito à vogal /o/, Tabela 2, o que pode ser tomado como indício de que se trata da mesma regra que atinge a átona final, cujo contexto estaria se ampliando, como se o sistema estivesse em busca da regularização.

\begin{tabular}{l|c|c|c|c}
\hline & Fator & Aplic/Total & $\%$ & Peso Relat. \\
\hline Vogal /o/ & Labial (cômodo) & $371 / 456$ & 81 & 0,56 \\
\cline { 2 - 5 } & Coronal (catástrofe) & $23 / 46$ & 50 & 0,27 \\
\cline { 2 - 5 } & s/z (êxodo) & $1 / 6$ & 17 & 0,09 \\
\cline { 2 - 5 } & Dorsal (horóscopo) & $9 / 27$ & 33 & 0,13 \\
\hline TOTAL & & $404 / 535$ & 76 & \\
\hline
\end{tabular}

Input: 0,79

Significância: 0,000

Tabela 2: Elevação da postônica não final /o/ (Vieira 2002:134) 


\begin{tabular}{|c|c|c|c|c|}
\hline Vogal /e/ & Fator & Aplic./Total & $\%$ & Peso Relat. \\
\hline \multirow[t]{3}{*}{ Vogal /e/ } & Labial(número) & $69 / 173$ & 40 & 0,53 \\
\hline & $\begin{array}{c}\text { Coronal } \\
\text { (alfândega) }\end{array}$ & $8 / 69$ & 12 & 0,30 \\
\hline & s/z (cócega) & $14 / 23$ & 61 & 0,84 \\
\hline TOTAL & & $91 / 265$ & 34 & \\
\hline
\end{tabular}

Input: 0,32

Significância: 0,006

Tabela 3: Neutralização da postônica não-final vogal /e/ (Vieira 2002:140)

A análise estatística, na linha de Labov, realizada por Maria José Vieira, revelou que ambas as vogais /e, o/ são substituídas por vogal alta, embora os contextos que favorecem uma e outra sejam diferenciados. A vogal /o/, postônica não final, eleva-se relativamente mais quando o onset da sílaba é uma labial, enquanto a vogal /e/, por sua vez, eleva-se relativamente mais quando o onset da sílaba é a contínua coronal s/z. Uma e outra tem seu contexto favorecedor.

Embora haja palavras mais resistentes, vértebra e cátedra são exemplos, figuram casos como alfândiga alfândega, epêntise epêntese, córrigo córrego, prótise $\sim$ prótesi e outros, ao lado de fósfuro $\sim$ fósforo e abóbura abóbora. Note-se, todavia, que muitas proparoxítonas são termos técnicos que tendem a preservar a integridade de seus segmentos, talvez em função do uso restrito a uma comunidade homogênea, figurando como um entrave à generalização.

Talvez a observação mais importante esteja no fato de que /o/ venha se mostrando mais sensível ao processo do que /e/ por motivação contextual. A vogal /o/ na cercania de uma labial /f,v,p,b,m/, como em abóbora e fósforo, muda para /u/ com frequiência, como se a comunhão de um traço, a labialidade, fosse um fator que estivesse favorecendo a regra que, por ser variável, pode ocorrer também em contextos não esperados como em pérola. Uma consoante velar que se diz alta porque pronunciada com o dorso da língua levantado poderia favorecer a regra como o faz em prólogo, mas tende a deixar de fazê-lo em fonólogo, em variedades do Sul. Tem, pois, todas as características de uma regra variável de alçamento.

A suposta regra de neutralização da pretônica não final, envolvendo apenas a vogal posterior, pode ser mero efeito de frequiência, pois palavras como fósforo e abóbora são de uso constante na fala popular. Mas o que os resultados da análise estatística apontam é que na pauta da postônica não final, a elevação de ambas as vogais vem ocorrendo, semelhantemente ao 
que ocorre na átona final, embora ainda não se tenha manifestado como regra geral em nenhuma variedade do português brasileiro, diferentemente do que ocorre com a pauta final. Note-se que o contraste fonológico entre médias e altas foi perdido na postônica não-final, da mesma forma que na átona final, mas a opção pela vogal alta é que vem encontrando resistência.

Os argumentos apresentados até agora são de base fatual, pois fundamentam-se em dados analisados estatisticamente. Passemos aos argumentos fonológicos.

Em primeiro lugar, observemos que, assim como na pretônica, não faltam exemplos que apontam para a relação entre as vogais neutralizadas e as preservadas, seja /o/ seja /e/:

(7) perolar fosforear alfandegário

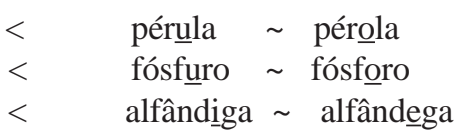

Em segundo lugar, a postônica final e não final apresentam traços idênticos no que diz respeito a características que identificam neutralizações.

Segundo McCarthy (1999), a neutralização deve ser identificada por três fatores:

1- A posição em que o contraste é mantido e a posição complementar em que o contraste é neutralizado

2- A natureza do contraste

3- $\mathrm{O}$ resultado final

Lidimamente identificam-se com características próprias os fatores da neutralização da pretônica:

1- O contraste é mantido na tônica e anulado em toda a pauta átona.

2- O traço anulado é o que distingue as vogais médias entre si. Em termos de Câmara è a distinção entre a média aberta e média fechada; em termos de Wetzels, é [aberto3].

3- O resultado é um sistema de cinco vogais. Converte-se, pois, um sistema de sete vogais em um sistema de cinco vogais.

Observemos agora a coincidência de fatores para as duas pautas restantes:

(8) Átona final

1- O contraste é mantido na tônica e pretônica e anulado na átona final.

2- O traço anulado é o que distingue as vogais médias e altas em termos de Câmara; em termos de Wetzels é [+aberto2].

3- O resultado é um sistema de três vogais. Um sistema de cinco vogais 
converte-se em um sistema de três vogais.

(9) Postônica não-final (com base nos dados estatísticos supramencionados)

1. O contraste é mantido na tônica e na pretônica.

2. O traço anulado é o que distingue as vogais médias e altas, em termos de Câmara; em termos de Wetzels é [aberto2]

3. O resultado é um sistema de cinco vogais, variando com um sistema de três vogais.

Como vemos, os fatores são os mesmos em uma e outra posição da postônica (8) e (9). A diferença reside no item 3, pois a neutralização da átona final com o privilegio da vogal alta em sua manifestação externa é regra geral para muitos dialetos ou variedades do português. Rio de Janeiro e Porto Alegre foram citados. Mas a neutralização da postônica não-final, como manifestação externa da vogal alta, é uma regra variável em qualquer comunidade de fala.

Com as evidências apresentadas, podemos dizer que a neutralização em favor das vogais altas compreende somente duas regras: a que reduz o sistema a cinco vogais e a que reduz o sistema a três vogais. Essa, no que diz respeito à opção pela vogal alta, tende a estender-se para a postônica não-final, em busca da regularização do sistema, criando as flutuações referidas.

EM SUMA o português brasileiro conta com duas regras de neutralização e não três como se vinha postulando. Trata-se de um sistema vocálico de sete vogais que se manifesta plenamente em posição tônica e dois subsistemas átonos de cinco e três vogais, que estão representados no esquema de Clements (3). O sistema de cinco vogais tem sua plenitude na pretônica e o sistema de três vogais na átona final. Na postônica não-final, flutuam os dois sistemas átonos, o de cinco e o de três vogais.

E-mail: bisol@pop3.pucrs.br Recebido em dezembro de 2002

Aprovado em maio de 2003

\section{REFERÊNCIAS BibLIOGRÁFICAS}

Camara JR, J. M. 1977. Para o estudo da fonêmica portuguesa. Rio de Janeiro: Padrão.

Clements, G. N. 1991. Vowel height assimilation in Bantu languages. In: K. HUB-BARD (Ed.) BLS 17S: Proceedings of the Special Session on African Languages Structures: 25-64. Berkeley Linguistic Society. University of California. 
JonEs, D. 1957. An outline of English phonetics. 8.ed. Cambridge: Heffer \& Sons.

MCCARTHY. J. 1999. Introductory OT. On CD-ROM (version 1.0).

Martinet, A. 1964. Economía de los cambios fonéticos. Tratado de fonologia diacronica. Madrid: Editorial Gredos.

VIEIRA, M.J.B. 2002. As vogais médias postônicas. Uma análise variacionista. In: L. Bisol \& C. Brescancini. Fonologia e Variação. Recortes do português brasileiro: 127-159. Porto Alegre: EDIPUCRS.

Wetzels, W. L. 1992. Mid Vowel Neutralization in Brazilian Portuguese. Cadernos de Estudos Lingüísticos,23. 19-55. Campinas: UNICAMP/ IEL. 